\title{
Device Cleaning and Infection Control in Aerosol Therapy
}

\author{
Catherine A O'Malley RRT-NPS
}

\author{
Introduction \\ Challenges With Device Cleaning \\ Awareness of Guidelines \\ Inconsistency of Guidelines \\ Manufacturer's Instructions: Are They Compatible With the Guidelines? \\ Infection-Control Recommendations for Aerosol Therapy and Add-On Devices \\ The Nebulizer \\ Add-On Devices: PEP and Valved Holding Chambers \\ The Metered-Dose Inhaler \\ The Powder Inhaler \\ The Pulmonary Function Testing Lab \\ What Is Happening in Real Life? \\ Teaching Device Cleaning \\ Verbal \\ Visual \\ Tactile \\ Written \\ RT Responsibility \\ Routine Checking for Microbial Colonization: Yes or No? \\ Summary
}

Aerosol delivery equipment used to administer inhaled medications includes the nebulizer, positive expiratory pressure devices added to the nebulizer, and valved holding chambers (spacers). These devices are semi-critical medical devices, and as such, infection prevention and control (IPC) guidelines recommend that they be cleaned, disinfected, rinsed with sterile water, and air-dried. There is confusion surrounding the care of aerosol devices because of inconsistencies in the various published IPC guidelines, lack of a standard of practice among institutions and respiratory therapists (RTs), and manufacturer's instructions for use of these devices are not always compatible with guidelines or practice. Challenges lie in awareness of IPC guidelines and establishing a standard for the care of aerosol delivery devices among all stakeholders/manufacturers, governments, vendors, and users. The latest IPC guideline from the Cystic Fibrosis Foundation, reviewed and endorsed by the Society for Healthcare Epidemiology of America and the Association for Professionals in Infection Control, has a recommendation for disposable nebulizers and a recommendation for reusable nebulizers. Reusable nebulizers should be cleaned, disinfected, rinsed with sterile water (if using a cold disinfectant), and air-dried between uses. The mouthpiece/mask of disposable nebulizers should be wiped with an alcohol pad, the residual volume should be rinsed out with sterile water after use, and the nebulizer should be replaced every $24 \mathrm{~h}$. The RT plays a significant and responsible role in providing and teaching aerosol therapy to patients. The RT and all stakeholders need to work together to provide a standard of care for the safe use of aerosol delivery devices. Key words: aerosol drug therapy; medical devices; nebulizers; inhalers; valved holding chambers; inhalation spacers; equipment contamination; infection prevention; infection control; respiratory therapy. [Respir Care 2015;60(6):917-930. (C) 2015 Daedalus Enterprises] 


\section{Device Cleaning and Infection Control in Aerosol Therapy}

\section{Introduction}

Aerosol therapy is an important and considerable aspect of respiratory care practice. The handling and care of the aerosol devices used in aerosol therapy are as important as delivering medications to the lungs. Aerosol delivery devices include nebulizers, spacers or valved holding chambers, and any add-on devices used during aerosol delivery, specifically positive expiratory pressure (PEP) therapy devices, many of which are designed for use during aerosol treatment. These devices are categorized as semi-critical medical devices because they come in contact with mucous membranes, and according to infection prevention and control (IPC) guidelines, semi-critical medical devices require thorough cleaning followed by high-level disinfection. ${ }^{1}$ The goal in aerosol therapy is to medicate, not contaminate. In addition to IPC guidelines, it is important to follow the instructions for use provided by the manufacturers of medical devices to maintain the integrity and function of the devices. Unfortunately, there can be discord between the manufacturers' recommendations and the guidelines, creating confusion and possible misuse of aerosol devices.

Here, I address the challenges of device cleaning and infection control in aerosol therapy, which include an awareness of evidence-based guidelines, consistency among the various guidelines, and compatibility between these guidelines and the recommendations of device manufacturers. Topics include the most current IPC recommendations for nebulizer care in the home and in the hospital; the guidance or lack thereof for other aerosol delivery devices, namely PEP devices and spacers; and information about real life practices, teaching tips, and a list of responsibilities for the respiratory practitioner when it comes to device cleaning and infection control in aerosol therapy. Finally, I address the question of whether aerosol devices and pulmonary function testing equipment should be routinely checked for microbial contamination.

Ms O'Malley is affiliated with the Ann \& Robert H Lurie Children's Hospital of Chicago, Chicago, Illinois.

Supplementary material related to this paper is available at http:// www.rcjournal.com.

Ms O'Malley presented a version of this paper at the 53rd RESPIRATORY CARE Journal Conference "Aerosol Drug Delivery in Respiratory Care," held June 6-7, 2014, in St Petersburg, Florida.

Ms O'Malley has disclosed relationships with PARI and Novartis.

Correspondence: Catherine Ann O'Malley RRT-NPS, Ann \& Robert H Lurie Children's Hospital of Chicago, 225 East Chicago Avenue, Box 58, Chicago, IL 60611-2605. E-mail: comalley@ luriechildrens.org.

DOI: $10.4187 /$ respcare. 03513

\section{Challenges With Device Cleaning}

\section{Awareness of Guidelines}

There are several evidence-based guidelines available from professional and nonprofit organizations: government, regulatory, and accrediting agencies, such as the American Association for Respiratory Care (AARC), Centers for Disease Control and Prevention (CDC)/Healthcare Infection Control Practices Advisory Committee (HICPAC), the World Health Organization (WHO), the Infectious Diseases Society of America, the Society for Healthcare Epidemiology of America (SHEA), the Association for Professionals in Infection Control and Epidemiology (APIC), and the Cystic Fibrosis Foundation. These organizations assemble committee members who are experts in their field to find and evaluate scientific evidence and knowledge and to publish recommendations for health-care providers to help them take better care of their patients. Recommendations for the care of respiratory equipment are included in these guidelines, with specific attention given to nebulizers.

In 2001, the Cystic Fibrosis Foundation convened an infection-control committee to revise and update their infection-control recommendations for people with cystic fibrosis $(\mathrm{CF})$, and their consensus document was published in 2003..$^{2}$ In this document, stringent recommendations are given for nebulizer care, and they applied to nebulizers used in the home and the hospital: clean, disinfect, rinse, and air-dry nebulizers between uses.

The challenge is to be aware of the guidelines. Before and following implementing the 2003 Cystic Fibrosis Foundation guidelines, Lester et $\mathrm{al}^{3}$ surveyed subjects with $\mathrm{CF}$ and respiratory therapists (RTs) on the use and maintenance of nebulizers. They found a wide disparity in cleaning methods among the subjects, which paralleled the diversity among the RTs' methods and instructions for nebulizer care. They concluded that there needs to be improvement in nebulizer care, that a standard method for nebulizer cleaning and disinfecting is imperative for home and hospital, and that awareness and education of both patients and staff need more focus in this regard. It was an awareness of the Cystic Fibrosis Foundation consensus document that inspired this study and the findings.

Like Lester et $\mathrm{al}^{3}{ }^{3} \mathrm{O}^{\prime}$ Malley et $\mathrm{al}^{4}$ investigated their institution's practice in light of the 2003 Cystic Fibrosis Foundation guidelines. They looked at their hospital's policy of changing disposable nebulizers every $24 \mathrm{~h}$ without any cleaning, disinfecting, or rinsing between treatments. The purpose of the study was to determine whether this practice was safe related to IPC for patients with CF (safe meaning that no pathogens important in CF were colonized in the nebulizers over a 24-h period). They found no pathogen growth and concluded that their practice was acceptable and safe. The point is that to provide the best 


\section{Device Cleaning and Infection Control in Aerosol Therapy}

care for patients, it is important to be aware of the current evidence-based guidelines. Awareness precipitates action and discovery.

Not all health-care professionals are aware of the guidelines. For example, Garber et $\mathrm{al}^{5}$ randomly surveyed CF center health-care professionals to determine what barriers existed in following the 2003 infection-control guidelines for $\mathrm{CF}$ and found that only $60 \%$ of respondents reported that they were aware of the guidelines. Similar findings were reported by Lugtenberg et $\mathrm{al}^{6}$ when investigating why general practitioners in the Netherlands do not adhere to national guideline recommendations. In addition to the lack of knowledge of the recommendations, they identified other barriers, such as disagreement with the recommendations, organizational constraints to following the recommendations, and ambiguity in the guidelines. Although there is more than one barrier to the implementation of infection-control guidelines in any healthcare setting, ${ }^{7}$ lack of awareness is a significant one. Change begins with awareness.

\section{Inconsistency of Guidelines}

There are noteworthy inconsistencies that exist among the recommendations for nebulizer care found in published guidelines, and the evidence is not entirely supportive, which creates confusion for practitioners. To illustrate, the following quotations are from active (as of mid-2014) published guidelines on nebulizer care.

The 2003 Cystic Fibrosis Foundation guideline states, "Between treatments on the same patient, disinfect, rinse with sterile water or filtered water $(0.2 \mu \mathrm{m})$, and air-dry small volume in-line or handheld medication nebulizers." ${ }^{2}$ The word clean is omitted in this statement; however, the text of the Cystic Fibrosis Foundation guideline clearly states the importance of cleaning before disinfection. Many of the references associated with this statement are studies that found nebulizers used in the home of subjects with CF to be contaminated with a variety of bacterial pathogens in the absence of adequate cleaning, disinfecting, and drying of the nebulizers. ${ }^{8-11}$ All of this evidence clearly supports a more stringent recommendation for nebulizer care in the home setting.

With respect to the hospital setting, the evidence of contaminated nebulizers referenced in the Cystic Fibrosis Foundation guideline describes several factors that contribute to contamination, such as the use of multi-dose bottles of medication, nebulizers remaining in line with the ventilator circuit and being contaminated with ventilatortubing condensate, lack of aseptic technique by clinicians, and poor adherence to handwashing. ${ }^{12-14}$ There is only one reference regarding bacterial contamination found in a hand-held nebulizer in a day-hospital setting. Vassal et al ${ }^{15}$ studied 44 subjects with $\mathrm{CF}$ and positive sputum cultures for Pseudomonas aeruginosa and found two thirds of the nebulizers to be contaminated with pathogens after a sin- gle use. The method described for collecting specimens was to rinse out the entire nebulizer system (nebulizer cup, corrugated tubing, and mouthpiece), homogenize the fluid, and then culture it. One could speculate that the mouthpiece played a role in the contamination. A study by Cobben et $\mathrm{al}^{16}$ supports this speculation. They studied a severe outbreak of $P$. aeruginosa from contaminated nebulizers, and the outbreak ceased after they adopted the policy of changing the mouthpieces every $24 \mathrm{~h}$.

The 2003 CDC/HICPAC guideline states, "Between treatments on the same patient: clean, disinfect, rinse with sterile water (if rinsing is necessary), and dry smallvolume in-line or hand-held nebulizers." 17 This statement is all inclusive: clean, disinfect, rinse, and dry between treatments. However, the references provided in this stringent recommendation do not support the need to clean and disinfect. ${ }^{18-20}$ Rather, the evidence in these references supports the use of sterile water for rinsing the nebulizer, air-drying after use, and avoidance of contaminated bottles of medication.

The 2004 CDC/HICPAC (revision) states, "Between treatments on the same patient, disinfect, rinse with sterile water, or air-dry small-volume in-line or hand-held medication nebulizers." 21 This statement is a revision of the 2003 CDC/HICPAC guideline, and the references are the same. Similar to the 2003 Cystic Fibrosis Foundation guideline, the word clean is omitted; however, the document recommends to "thoroughly clean all equipment and devices to be sterilized or disinfected." Interestingly, this statement is the same as that in the CDC guidelines from 1994. ${ }^{22}$ What is significant is that the wording has changed: "and" was replaced with "or." The change is important. It could be translated that you have a choice to disinfect and rinse between treatments or simply air-dry between treatments. Many hospital practices are congruent with the practice of simply rinsing nebulizers between treatments and allowing them to air-dry. ${ }^{23}$

The 2012 AARC clinical practice guideline states, "Jet nebulizers should be cleaned, rinsed with sterile water, and air-dried between treatments on the same patient." 24 This statement omits the word disinfect. In addition, "or" has again been replaced with "and." To date, this is the most recently published guideline by the AARC on the topic of aerosol delivery, and the references provided to support this statement are the same as the 2003 guidelines from CDC/HICPAC and the Cystic Fibrosis Foundation.

Is anyone confused? It helps to summarize the evidence referenced in the above guidelines with respect to nebulizer care. In the home setting, nebulizers are contaminated with bacterial pathogens in the absence of adequate cleaning, disinfecting, and drying. In the hospital setting, nebulizers become contaminated if subjected to ventilatortubing condensation or if tap water is used to wash/rinse them. One study showed that two thirds of hand-held dis- 


\section{Device Cleaning and Infection Control in Aerosol Therapy}

posable nebulizers used by subjects with $\mathrm{CF}$ and colonized with $P$. aeruginosa were contaminated after one use. Crosscontamination happens with the use of multi-dose bottles of medication between patients and the lack of aseptic technique and hand hygiene of clinicians.

\section{Manufacturer's Instructions: Are They Compatible With the Guidelines?}

The manufacturers of aerosol delivery devices include instructions for use in their packaging. There are two important aspects of the instructions to keep in mind when determining how best to clean and disinfect a device. First, the instructions are part of the labeling of the device that received clearance from the FDA. This is all very legal and does not allow the manufacturer to formally waiver from the instructions for use. Second, the manufacturer's instructions are important to maintain the function and integrity of the device. In other words, you do not want to destroy a device when trying to clean and disinfect it.

The clinician will find that instructions for use from the manufacturers are not always compatible with the IPC guidelines. A clear example of this is the instructions for disposable nebulizers, which are commonly used in the hospital setting. A typical instruction will recommend washing with dishwashing liquid and warm water, followed by rinsing with warm water and air-drying, but will offer no guidance for disinfection. In fact, it will state, "Do not sterilize." In defense, disposable equipment is not intended for prolonged use. It is manufactured for disposable use. The more important issue is the instructions recommending tap water as a final rinse. Unlike the IPC guidelines, manufacturers' instructions do not appear to be concerned with tap-water contaminants.

With respect to disinfection and tap-water use, instructions for reusable nebulizers are in conflict with the IPC guidelines as well. Instructions for reusable nebulizer equipment all recommend that the nebulizer parts be cleaned with soap and water, rinsed with tap water, and air-dried after use; however, they vary on the frequency recommended for disinfection. You will find instructions to disinfect daily, at the end of the treatment day, or every other day. This is in direct conflict with the IPC guidelines recommending that semi-critical medical devices (eg, nebulizers) be cleaned, disinfected, rinsed with sterile water (if using a cold disinfectant), and air-dried after each use. And again, there is the tap-water issue. Simply cleaning/rinsing with tap water between uses is not recommended because tap water is a known source of potentially pathogenic organisms. ${ }^{2}$ Using tap water for the soapand-water cleaning step is fine if you are going to follow this step with disinfection, but the final rinse of respiratory equipment should be with sterile water only.
Following the recommended frequency of cleaning and disinfecting equipment according to the IPC guidelines versus the manufacturers' instructions for use will not destroy the device. Standaert et $\mathrm{al}^{25}$ looked at the impact of repetitive use and cleaning of 4 models of disposable nebulizers and one reusable nebulizer in terms of their output and aerosol distribution after 100 cycles and found no clinically important change in performance. In fact, the reusable nebulizer maintained a 2-3 times higher output rate compared with the disposable nebulizers. What may impact the integrity of the nebulizer is the option of disinfection. For example, instructions are not going to recommend disinfection by a microwave if the device has metal components or boiling if the material of the device will warp or melt in the process. In this respect, it is important to use the disinfection option that the manufacturer permits.

Manufacturers' instructions for use are not always compatible with all of the disinfecting options in the guidelines and vice versa. For example, often you will read an instruction that will recommend Control III. Why? What is it? Control III contains benzylammonium chloride, which happened to be a popular antiseptic/disinfectant in the 1950s and 1960s, and perhaps it simply is an established/historical disinfectant that continues to be cleared by the FDA and recommended by manufacturers (personal communication, 2014, David Weber MD, Division of Infectious Disease, University of North Carolina, Chapel Hill, North Carolina). Control III is actually a poor disinfectant because it does not have broad activity, is slow in action, and is associated with pathogenic outbreaks. ${ }^{26}$ The Cystic Fibrosis Foundation does not recommend Control III.

Another frequently recommended/historical disinfectant is vinegar (acetic acid). Vinegar is effective in killing $P$. aeruginosa, but it is not effective in killing other potential pathogens, such as Staphylococcus aureus and Escherichia coli. Therefore, according to the Cystic Fibrosis Foundation guidelines, vinegar is not a recommended disinfectant for nebulizers. ${ }^{2}$

There are several choices of aerosol delivery devices on the market, and if possible, you want to use the one that meets all of your needs in terms of operation/effectiveness and infection control. Manufacturers have been aware and responsive to this need, which is a good trend and is in concordance with WHO (http://whqlibdoc.who.int/ publications/2003/9241546182.pdf, Accessed April 1, 2014), which states that the ideal conditions to ensure the safety and performance of medical devices is to have all stakeholders (ie, manufacturer, government, vendor, and user) share in the responsibility and cooperate/communicate with each other. Manufacturers that I have known personally that exemplify this statement are Smiths Medical (Watford, United Kingdom), PARI Respiratory Equipment (Midlothian, Virginia), and Monaghan Medical 


\section{Device Cleaning and Infection Control in Aerosol Therapy}

(Plattsburgh, New York). For example, the original vibratory PEP (oscillatory PEP) device, the Acapella vibratory PEP therapy system manufactured by Smiths Medical, is designed to be used in conjunction with an aerosol; however, it cannot be taken apart for proper cleaning, which I pointed out during an introductory in-service. Soon afterwards, they designed the Acapella Choice and Acapella Duet. These devices can be taken apart, cleaned, and disinfected in several ways that are compatible with the guidelines. PARI Respiratory Equipment, a well-known manufacturer of respiratory care products, including several types of reusable nebulizers that have been in many clinical trials, consulted with me to make sure that their instructions for use of the Altera, an electronic nebulizer specifically manufactured for use with the medication aztreonam (Cayston), included options that were compatible with the Cystic Fibrosis Foundation guidelines. And finally, Monaghan Medical contacted me to assist them in preparing their instructions for one of their new oscillating PEP devices, the Aerobika. As a result, the instructions for this device, which can be used with a nebulizer, have several options for disinfection that are compatible with the Cystic Fibrosis Foundation guidelines. Communication between stakeholders makes a better product for patients.

\section{Infection-Control Recommendations for Aerosol Therapy and Add-On Devices}

Collaboration and partnership among the various organizations are increasing. ${ }^{27}$ The most recent evidence-based IPC guideline, Infection Prevention and Control Guideline for Cystic Fibrosis: 2013 Update, ${ }^{28}$ was commissioned by the Cystic Fibrosis Foundation and intended for use by health-care personnel caring for patients with CF. This guideline includes relevant recommendations from the evidence-based guidelines of CDC/HICPAC, WHO, Infectious Diseases Society of America, and SHEA. In addition, the draft of this guideline was open for review by the CF and IPC communities, and it was reviewed and endorsed by SHEA and APIC. It is this guideline that I will use as a reference for the most current evidence-based recommendations for the care of aerosol delivery devices.

\section{The Nebulizer}

Earle H Spaulding categorized patient care items according to the degree of risk for infection involved in their use. ${ }^{1}$ The categories are: critical (items that enter sterile tissue or the vascular system), semi-critical (items that come in contact with mucous membranes or non-intact skin), and non-critical (items that come in contact with intact skin but not mucous membranes). The nebulizer is a semi-critical item and is often the example given for respiratory equipment used in the guidelines. The nebulizer also happens to be the target of much research; therefore,
Table 1. Recommended Steps for Nebulizer Cleaning and Disinfecting in the Home

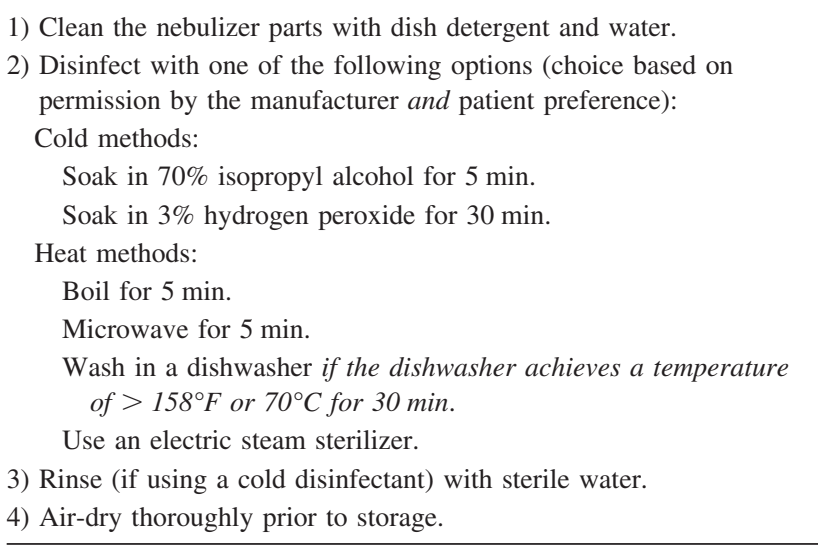

there are data to support IPC recommendations on its use and care.

General rules to follow for all nebulizers are: 1) Nebulizers are for single-patient use only; 2) always use an aseptic technique when handling the nebulizer and dispensing the medication; and 3) single-dose vials of medication are always preferred. If multi-dose bottles are used, follow careful instructions and technique to prevent medication contamination.

In the Home Setting. The steps recommended for nebulizers used in the home setting are to clean, disinfect, rinse (if rinsing is needed), and air-dry after each use (Table 1). The first step is to clean the nebulizer parts with dish detergent and water. This step is not simply a soak, but a good old-fashioned soap-and-water washing to remove organic and inorganic debris. Ideally, this step should be performed soon after use, but if this is not possible, then at least rinse the nebulizer parts well with water to prevent the medication/debris from drying onto the plastic, which would make cleaning more difficult. As mentioned earlier, tap water is acceptable to use for the cleaning step, if disinfection will follow.

The second step is to disinfect. There are several options for disinfecting: heat methods and cold soaking methods (see Table 1). These options are recommended based upon the fact that they are effective in killing organisms and they are recognizable methods/materials in the home setting. It is important for the patient/family to choose an option that works well for them and one that the manufacturer of the device permits.

The third step is to rinse the nebulizer with sterile water if the choice for disinfecting is to use a cold method disinfectant. The two recommended disinfectants are 3\% hydrogen peroxide and 70\% isopropyl alcohol. For disinfection to be effective, the nebulizer parts must be soaked for the recommended length of time: $5 \mathrm{~min}$ in hydrogen per- 


\section{Device Cleaning and Infection Control in Aerosol Therapy}

Table 2. Recommendations for Nebulizer Care in the Hospital

Hand-held disposable nebulizers:

1) After each use, rinse out the residual volume with sterile water and wipe the mask/mouthpiece with an alcohol pad.

2) Discard the nebulizer every $24 \mathrm{~h}$.

Hand-held reusable/durable nebulizers (home nebulizers):

1) After each use, clean, disinfect, rinse with sterile water (if using a cold disinfectant), and air-dry away from the sink

2) After each use, the nebulizer can be reprocessed, such as steam sterilization or autoclave, if the reprocessing is performed according to the manufacturer's instructions and the Cystic Fibrosis Foundation recommendations for home care and if the nebulizer can be returned to the patient in time for the next treatment.

oxide or $30 \mathrm{~min}$ in isopropyl alcohol. ${ }^{28}$ The liquid disinfectants will lose activity over time; therefore, how often these solutions can be reused is uncertain, and again, only sterile water should be used for the final rinse because tap water has known potential contaminants. ${ }^{2}$ It is important to note that distilled water is not sterile water. Distilled water is processed to remove many impurities and minerals, but it can become contaminated with Burkholderia cepacia complex during the processing. ${ }^{2}$

The fourth and final step is to air-dry the nebulizer parts. It is important to thoroughly air-dry the nebulizer parts before storage because storing equipment when it is wet can be a favorable environment for bacterial growth. ${ }^{2}$ Shake the nebulizer parts well, and lay each part out to air-dry, such as on top of paper towels on a clean counter. Care needs to be taken not to contaminate the parts after they have been cleaned and disinfected. Contamination can be avoided by good handwashing and not touching the inside sections of the device when laying them out to dry or when reassembling (aseptic technique).

In the Hospital Setting. There are two types of nebulizers: disposable and reusable. Disposable nebulizers are the most common type of nebulizer used in the hospital setting. However, there are some hospitals that may also use reusable nebulizers, which are more durable and typically used in the home setting. Actually, some inhalation medications require a specific nebulizer system for delivery. For example, aztreonam requires the Altera nebulizer for administration, which is an electronic reusable nebulizer. As a result, the current IPC guidelines of the Cystic Fibrosis Foundation have a recommendation for both disposable and reusable nebulizers (Table 2).

Disposable Nebulizers. The recommendation for disposable nebulizers used in the hospital setting is to rinse the residual medication out with sterile water, wipe the mouthpiece or mask with an alcohol pad after each use, and discard the disposable nebulizer after $24 \mathrm{~h}$. There is evi-
Table 3. In-Patient Plan for Reprocessing the Altera Nebulizer Used With Aztreonam

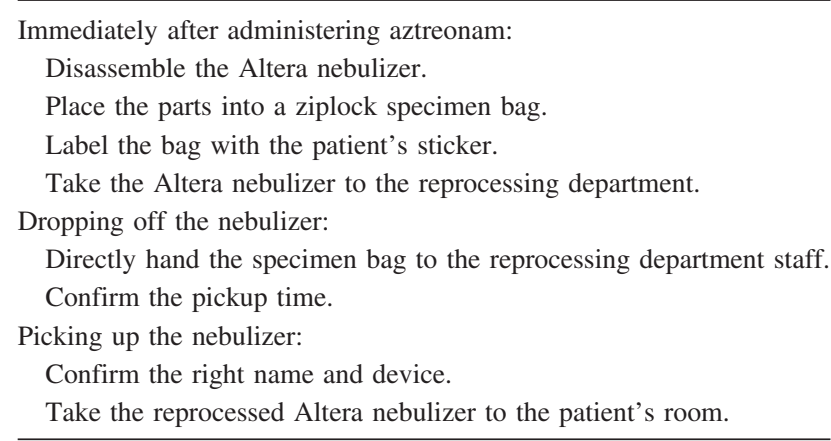

dence to support using a disposable nebulizer for up to $24 \mathrm{~h}$. O'Malley et $\mathrm{al}^{4}$ investigated the practice of using a disposable nebulizer in the hospital for a 24 -h period without any cleaning or disinfecting between uses and discovered that there was no growth of bacteria.

This finding is a welcome one since disposable equipment is not designed for reprocessing, particularly with respect to disinfecting, and is more congruent with current hospital practices. ${ }^{23}$ What is new and different in the Cystic Fibrosis Foundation guideline is the recommendation to wipe a nebulizer's mouthpiece or mask with an alcohol pad. This specific recommendation does not have an evidence-based reference attached to it; however, there is evidence that wiping a device with $70 \%$ alcohol can be an effective infection prevention practice. ${ }^{29}$ In addition, removing organic debris from the mask or mouthpiece should make the following aerosol treatment more pleasant for the patient.

Reusable Nebulizers. The recommendation for reusable/durable nebulizers in the hospital setting is the same as in the home setting: clean, disinfect, rinse (if using a cold disinfectant), and air-dry between treatments. This process can be done in the patient's room if hospital policy permits and if this responsibility can be delegated appropriately. For example, a parent or caregiver who stays with the patient while in the hospital may agree to the responsibility for nebulizer care, or the RT staff can commit to the obligation. The alternative is to have the hospital's reprocessing department handle the cleaning and disinfecting of reusable nebulizers. This arrangement will need an in-patient plan in place (Table 3). The reprocessing department requires instructions for use from the manufacturer of the nebulizer to reprocess the nebulizer correctly. The staff and reprocessing department will also need to communicate and cooperate with a plan that results in an appropriately disinfected device being returned to the correct patient at the correct time. 


\section{Device Cleaning and Infection Control in Aerosol Therapy}

\section{Add-On Devices: PEP and Valved Holding Chambers}

Add-on devices refer to PEP devices and valved holding chambers, also known as spacers, used in conjunction with aerosol therapy. These devices are semi-critical medical items; they come in contact with mucous membranes. They are a vehicle for aerosolized particles that enter the lower airways, and as such, they should be subject to the same recommendations as nebulizers: clean, disinfect, rinse, and air-dry between uses.

In theory, PEP devices used alone (ie, without an aerosol) are less invasive. However, if you add them to a nebulizer, it is important to treat them as a nebulizer in terms of cleaning and disinfecting. Many of the oscillating PEP devices on the market (eg, Acapella and Aerobika) can be cleaned and sterilized much the same way as reusable nebulizers. The manufacturers of these devices have taken into consideration the IPC guidelines, and with compatible instructions for use. The devices can be taken apart for thorough cleaning and disinfected in several ways, including heat options that are compatible with the current guidelines for IPC. For this reason, they make a good choice for an add-on PEP device.

Valved holding chambers are more difficult to navigate between the IPC guidelines and manufacturers' instructions for use. The purpose of a valved holding chamber is to improve drug delivery, and its use in respiratory care is inarguable. ${ }^{30}$ However, it is a semi-critical medical device, which warrants that it be cleaned, disinfected, rinsed, and air-dried between uses. In contrast, the manufacturers' instructions recommend washing the valved holding chamber with soap and water once a week. There is published evidence that bacterial contamination is common in spacer devices used in the home setting. Cohen et al ${ }^{31}$ investigated spacers used by 62 children with asthma and found that $35 \%$ of the spacers and $25 \%$ of the masks were contaminated with microorganisms: P. aeruginosa, S. aureus, and Klebsiella pneumoniae. The investigators concluded that spacer devices should be cleaned and dried after each use.

With respect to cleaning the valved holding chambers, there are a few other issues and controversies. First, how much soap (detergent) should one use when cleaning the spacer? In a review article regarding electrostatics and inhaled medications, ${ }^{32}$ the authors suggest that the detergent concentration is not important: that a few drops is all that is needed, which was based on a study by Piérart et al. ${ }^{33}$ These investigators used a wide range of detergent concentrations and did not find a difference in fine particle delivery. ${ }^{32,33}$ Second, should the soap be rinsed off or allowed to remain on the device to reduce the electrostatic charge in the spacer? The literature states the benefit of not rinsing the detergent off after washing and to simply wash in detergent and allow the device to air-dry. ${ }^{30,32}$ The reason for not rinsing the detergent off is to protect against electrostatic charge, which can result in inconsistent medication delivery. However, not rinsing the detergent off seems to negate the purpose of cleaning the device. After all, rinsing is a key step in the cleaning and disinfecting. In addition, there is the potential for contact dermatitis from the detergent. ${ }^{30,32}$ The most plausible solution for IPC is to use a spacer device that is made of antistatic material, where one can follow the appropriate IPC recommendation and avoid possible contact dermatitis from the detergent.

There are aerosol delivery devices used in the hospital setting that lack IPC research. The devices of considerable concern include valved holding chambers, PEP-aerosol combination therapies such as the MetaNeb circuit (HillRom, St Paul, Minnesota), and electronic vibrating mesh nebulizers placed in line with the ventilator circuit. Unlike traditional jet nebulizers, electronic nebulizers are not subject to ventilator-tubing condensate. In addition, there is the risk of ventilator-associated pneumonia every time the circuit is opened; therefore, one must consider the risk/benefit ratio when deciding how often to replace this type of in-line nebulizer. I am frequently faced with clinicians wondering how to clean, disinfect, or replace these devices. In the absence of evidence, the correct answer is uncertain, and again, the manufacturers' instructions for use are in conflict with IPC guidelines for semi-critical medical devices. What is the solution to this dilemma? To follow the ideal principle stated by WHO, all stakeholders need to communicate and share in the responsibility to deterimine the best practice for the safe use and performance of these devices in the hospital setting. Research anyone?

\section{The Metered-Dose Inhaler}

The metered-dose inhaler (MDI) has an actuator, also known as the boot, and a canister that contains the pressurized medication. There are specific cleaning instructions for the actuator that health-care professionals and patients need to know. ${ }^{34}$ Manufacturers recommend rinsing the actuator well under warm running water for about $30 \mathrm{~s}$ on one end and $30 \mathrm{~s}$ on the other at least once a week, and the metal canister is not to get wet; it should be set aside. Although manufacturers refer to this instruction as cleaning the device, the purpose for rinsing the actuator has nothing to do with IPC. It has to do with removing medication buildup in the actuator that can block the spray of medication. Chlorofluorocarbon propellants in MDIs were switched to hydrofluoroalkane propellants, and as a result, there may be an issue with the chlorofluorocarbonfree actuators clogging. ${ }^{30,35}$ A blocked actuator is indeed a problem, but so is running tap water. Again, tap water 


\section{Device Cleaning and Infection Control in Aerosol Therapy}

should not be the final rinse for respiratory equipment. Admittedly, flushing the actuator with running sterile water may be a bit difficult/tedious to accomplish. What is the solution?

There are institutions that employ the common canister protocol, which is a cost-saving strategy used in hospitals and clinics to deliver MDI medications or to teach MDI technique using a placebo MDI. In both scenarios, the MDI is reused between patients, along with an individual valved holding chamber. ${ }^{29}$ If using the MDI with a singleuse, patient-specific spacer device, the MDI is no longer categorized as a semi-critical medical device and, in this case, would be considered a non-critical medical device. ${ }^{1}$ According to the CDC, non-critical medical devices with a smooth hard surface can be decontaminated where they are used and do not require reprocessing. Seventy percent alcohol is an approved disinfectant for non-critical medical devices, and the recommendation is to have an exposure time of at least $1 \mathrm{~min}$. Nevertheless, the concern with cross-contamination with the common canister protocol has been addressed in several investigative studies. ${ }^{29,36}$ Many have shown no growth when the MDI canister and actuator are wiped well with a $70 \%$ alcohol pad. The overall conclusion by APIC (http://www.ismp.org/newsletters/ acutecare/articles/20090409.asp, Accessed August 11, 2014) is that hospitals and their infection control teams should discuss and analyze their processes, and if they choose to use a common canister protocol, they should emphasize following a protocol that includes hand hygiene and wiping the MDI with alcohol before and after use between patients. Perhaps, wiping one's personal MDI (actuator and canister) with an alcohol pad would be a safer option than rinsing it under running tap water.

\section{The Powder Inhaler}

Powder inhalers should not get wet. It is essential to keep these devices dry because any wetness can inhibit proper function and delivery of the powder medication. Hand hygiene before use, wiping the mouthpiece off with a dry clean cloth such as a paper towel, and proper storage are necessary.

\section{The Pulmonary Function Testing Lab}

Aerosol therapy conducted in the pulmonary function lab is for testing purposes only, such as a methacholine challenge or a bronchodilator response. The aerosol delivery devices used to conduct the test should be singlepatient use only. At the end of testing, the devices should be discarded or dispensed to the patient with instructions on use, including cleaning and disinfecting.

\section{What Is Happening in Real Life?}

A survey was sent randomly to respiratory care directors and RTs across the country (see the supplementary materials at http://www.rcjournal.com). The purpose of the survey was to gather information on current practices related to aerosol delivery devices. Unfortunately, the survey response was only $13 \%$, which was not significant enough to draw general conclusions from the results.

However, calculations based on these data provide some insight. 1) Ninety-three percent of hospitals use disposable nebulizers. 2) Replacing disposable nebulizers varies between hospitals: daily (20\%), every $2-3 \mathrm{~d}(27 \%)$, and weekly (29\%). The outliers include $6 \%$ that never replace them, and 3\% that replace them after every use. Fifteen percent mentioned replacing them daily if the patient has a particular diagnosis, such as CF. 3) Most hospitals (36\%) do nothing with nebulizers between treatments, followed by $31 \%$ that rinse with sterile water and $15 \%$ that rinse with tap water. Other practices reported include air-drying (7\%); shaking out residual volume (7\%); disposal (3\%); and cleaning, disinfecting, rinsing with sterile water, and air-drying (only 1\%). 4) Response rates were similar regarding whether the RT or the home-care representative is responsible for teaching nebulizer care in the home. 5) Most RTs (33\%) recommend that nebulizers in the home be cleaned daily, $28 \%$ recommend after each use, $12 \%$ recommend weekly, $9 \%$ recommend every $2-3 \mathrm{~d}$, and $13 \%$ do not know. 6) Most RTs (40\%) recommend that nebulizers in the home be disinfected weekly, $25 \%$ recommend daily, $13 \%$ recommend every $2-3$ d, $3 \%$ recommend after each treatment, and 15\% do not know. 7) Most RTs (55\%) simply store the spacer device in the ziplock bag between uses in the hospital, and 7\% clean the mask/mouthpiece with an alcohol pad before storing in the ziplock bag. 8) Most RTs (60\%) never replace spacer devices used in the hospital, and 9\% replace them weekly. 9) RTs (60\%) are responsible for teaching spacer device care, followed by home-care representatives (17\%). Twelve percent of the people who responded do not know who teaches spacer device care. 10) RTs (55\%) routinely check respiratory equipment (including the pulmonary function testing lab) for microbial contamination, and $45 \%$ do not.

Based on this preliminary data, my assessment and recommendations are: 1) Practices for the care of aerosol delivery devices among RTs and hospitals lack a standard. 2) The stakeholders (ie, hospital, RTs, and home-care representatives) need to be aware of the IPC guidelines on the recommendations for cleaning and disinfecting of semicritical medical devices and work together to practice a standard that ensures the safe use of these devices to best serve the patient. 3) Tap water should never be used for the final rinse of medical devices. 


\section{Device Cleaning and Infection Control in Aerosol Therapy}

\section{Teaching Device Cleaning}

I hear and I forget. I see and I remember. I do and I understand.-Confucius $450 \mathrm{BC}$

The cleaning and disinfecting of aerosol devices are learned skills, and people learn in a variety of ways. To meet everyone's needs, it is important when teaching a skill that you appeal to all of the learning styles: verbal, visual, tactile, and written.

\section{Verbal}

Instructions usually include a verbal description. According to the American Medical Association Foundation, there are ways health-care providers can improve communication with patients. ${ }^{37}$ These recommendations include slow pacing, the use of plain nonmedical language, limiting instruction to only what the patient needs to know, and repetition. This is not dumbing down the information; it is respecting the patient's need to clearly understand the material to avoid any misunderstanding.

The instruction for cleaning and disinfecting an aerosol device should include: 1) the purpose of cleaning, disinfecting, and drying the device; 2) an understanding that the patient will be provided with written instructions; 3) the importance of hand hygiene when handling the devices; 4) the steps for device care: cleaning, disinfecting, rinsing (if using a cold disinfectant), and drying; 5) a detailed explanation of the options for disinfecting (allow the patient to decide on the one that best suits them and the device); 6) repeat instructions; and 7) have learner repeat instructions.

\section{Visual}

The instructions for cleaning and disinfecting aerosol devices should include a visual demonstration of the equipment: 1) taking the device apart for cleaning, 2) laying the parts out for drying, and 3) putting the device back together without contaminating the inside sections of the device.

\section{Tactile}

To learn the skill of handling the equipment properly, the patient (or parent or caregiver) needs to return the demonstration provided above. This is learning by doing, which is key for understanding the lesson.

\section{Written}

People learning a skill can relax during the instruction if they are aware that they will have written instructions on cleaning, disinfecting, and drying the aerosol device. Hand- outs are an important tool for teaching a skill, and health education reading materials are more effective if the writing is at a 6 th-8th grade reading level. ${ }^{38}$ In addition to the writing level, there are a few other tips for creating an effective handout ${ }^{37}$ : 1) keep it simple, 2) keep it short, 3) limit content to key information only (what patients need to know), 4) use words that a nonmedical person understands, and 5) use a 12-14-point font size.

\section{RT Responsibility}

RTs are ideally suited to educate patients on aerosol therapy and infection control. RTs have been educated in school and at their institutions on the best practices for aerosol delivery and the importance of infection control. RTs have clinical knowledge and experience in providing aerosol therapy to patients and are in a position to set examples for the correct use and care of aerosol therapy devices. However, there are challenges that need to be addressed by the profession. As Lester et $\mathrm{al}^{3}$ pointed out in their survey study, a standard for cleaning, disinfecting, and replacing aerosol delivery devices needs to be established and put into practice. In addition, it is well documented that health-care providers' knowledge of aerosol device use is inadequate. ${ }^{30}$

To take on the responsibility and opportunity to educate and provide instructions to patients on the use and care of aerosol delivery devices, the RT must have a firm understanding of how to correctly use the devices. There are several resources available to the RT, such as IPC guidelines, manufacturers' instructions for use, journal articles and peer-review literature, professional organizations, hospital policies and procedures, and their clinical educators. In addition, the RT must be aware of the many patientrelated issues that exist in aerosol therapy, which include (but are not limited to) poor technique, mismatch of patient and device, and adherence. ${ }^{30}$ Finally and of high importance, the RT must have a firm awareness and understanding of the IPC guidelines to instruct patients on how and why to care for aerosol devices between uses (Table 4).

Not every RT wants to be in charge of patient education. Nevertheless, the RT is in the position of educating patients by virtue of providing aerosol therapy. However, the RT is not alone. RTs are members of the medical team, and it is in all of the stakeholders best interest to play a role in providing patient education. As pointed out in "Problems with inhaler use: a call for improved clinician and patient education,"39 it is the prescribing clinician and the dispensing pharmacist who have the primary responsibility for patient education. The authors of this paper concluded, "As patient-care advocates, we need to educate administrators and legislators of the need to make time for 


\section{Device Cleaning and Infection Control in Aerosol Therapy}

Table 4. Links to Infection Prevention and Control Guidelines

\begin{tabular}{l}
\hline \hline Centers for Disease Control and Prevention \\
www.cdc.gov/mmwr/preview/mmwrhtml/rr5303a1.htm \\
American Association for Respiratory Care \\
rc.rcjournal.com/content/57/4/613.full.pdf \\
Healthcare Infection Control Practices Advisory Committee \\
www.cdc.gov/hicpac/pdf/guidelines/disinfection_nov_2008.pdf \\
Cystic Fibrosis Foundation \\
www.jstor.org/stable/10.1086/676882 \\
Accessed February 12, 2015. \\
\hline
\end{tabular}

Table 5. Respiratory Therapist Responsibilities

Practice and teach hand hygiene.

Practice and teach aseptic technique when using aerosol delivery devices.

Be knowledgeable of the standard procedures for using aerosol delivery devices.

Be aware of the infection prevention and control guidelines/recommendations for the handling and care (ie, cleaning/disinfecting/drying) of aerosol delivery devices.

Understand the patient-related issues in aerosol therapy to enhance your patient education efforts.

Be a patient advocate. Seek support and guidance from all stakeholders (hospital administrators, medical teams, manufacturers, professional organizations, and government legislatures) to assist you in providing quality care, education, and time for the patients you serve.

teaching and provide resources so that proper education is the norm rather than the exception" (Table 5).

\section{Routine Checking for Microbial Colonization: Yes or No?}

In general, the correct answer is no. If you are following the recommended IPC procedures/processes between patients in the pulmonary function testing lab or elsewhere, there is no need to look for microbes. If you are doing all of the correct steps for IPC, the important question to ask is what are you going to do differently if you do find microbes?

The recommendation for infection and microbiologic surveillance by the CDC/HICPAC states, "In the absence of specific clinical, epidemiologic, or infection-control objectives, do not routinely perform surveillance cultures of patients or of equipment or devices used for respiratory therapy, pulmonary-function testing, or delivery of inhalation anesthesia."17 There are situations that warrant looking for microbial contamination. An outbreak, for example, requires a thorough plan to investigate and locate the source of the outbreak to control and/or stop it. This requires a strategic operation or plan to determine the source of contamination. Is it geographical, temporal, organiza- tional, or water-borne (personal communication, 2014, Angie Rupp, Infection Control Director, Ann \& Robert H Lurie Children's Hospital of Chicago, Chicago, Illinois)?

Another situation that warrants looking for microbes is if there is a burning question in need of an answer or to support or add to the literature: in other words, a research study. I personally had a burning question when I surveyed the nebulizers used by subjects with CF in the hospital setting. ${ }^{4} \mathrm{I}$ wanted to know if our hospital policy for nebulizer care was safe for the patients, and this required that I check the nebulizers for bacteria. It was not a routine check.

What is important and successful is to routinely check or audit adherence to recommended IPC practices and quality-improvement programs in the health-care setting. Such audits are now required by credentialing organizations, namely The Joint Commission. ${ }^{28}$ These audits are not punitive; rather, they are designed to provide feedback to the health-care team and reinforce implementation of IPC guidelines for patient safety.

\section{Summary}

My best effort in this article is to share with you the current IPC guidelines of the Cystic Fibrosis Foundation for nebulizer care, and my intention is for clinicians to be aware of these guidelines. The RT is in the first-line of patient education and has a critical role in patients successfully using their aerosol devices correctly and safely. My hope is that clinicians embrace their profession and the resources available to work toward a standard in aerosol device cleaning and infection control. It is a team effort. All stakeholders (respiratory care departments, hospital administrators, infection-control teams, physicians, nurses, manufacturers, governments, professional organizations) need to cooperate, communicate, and share in the responsibility of ensuring the safe use of aerosol delivery devices.

\section{REFERENCES}

1. Rutala WA, Weber DJ, Healthcare Infection Control Practices Advisory Committee (HICPAC). Guideline for disinfection and sterilization in healthcare facilities, 2008. http://www.cdc.gov/hicpac/pdf/ guidelines/disinfection_nov_2008.pdf. Accessed February 12, 2015.

2. Saiman L, Siegel J, Cystic Fibrosis Foundation. Infection control recommendations for patients with cystic fibrosis: microbiology, important pathogens, and infection control practices to prevent patientto-patient transmission. Infect Control Hosp Epidemiol 2003;24(5 Suppl):S6-S52.

3. Lester MK, Flume PA, Gray SL, Anderson D, Bowman CM. Nebulizer use and maintenance by cystic fibrosis patients: a survey study. Respir Care 2004;49(12):1504-1508.

4. O'Malley CA, VandenBranden SL, Zheng XT, Polito AM, McColley SA. A day in the life of a nebulizer: surveillance for bacterial growth in nebulizer equipment of children with cystic fibrosis in the hospital setting. Respir Care 2007;52(3):258-262. 


\section{Device Cleaning and Infection Control in Aerosol Therapy}

5. Garber E, Desai M, Zhou J, Alba L, Angst D, Cabana M, et al. Barriers to adherence to cystic fibrosis infection control guidelines. Pediatr Pulmonol 2008;43(9):900-907.

6. Lugtenberg M, Zegers-van Schaick JM, Westert GP, Burgers JS. Why don't physicians adhere to guideline recommendations in practice? An analysis of barriers among Dutch general practitioners. Implement Sci 2009;4:54.

7. Savant AP, O'Malley C, Bichl S, McColley SA. Improved patient safety through reduced airway infection rates in a paediatric cystic fibrosis programme after a quality improvement effort and infection prevention and control measures. BMJ Qual Saf 2014;23(Suppl 1): i73-i80.

8. Hutchinson GR, Parker S, Pryor JA, Duncan-Skingle F, Hoffman PN, Hodson ME, et al. Home-use nebulizers: a potential primary source of Burkholderia cepacia and other colistin-resistant, Gramnegative bacteria in patients with cystic fibrosis. J Clin Microbiol 1996;34(3):584-587.

9. Pitchford KC, Corey M, Highsmith AK, Perlman R, Bannatyne R, Gold R, et al. Pseudomonas species contamination of cystic fibrosis patients' home inhalation equipment. J Pediatr 1987;111(2):212-216.

10. Rosenfeld M, Joy P, Nguyen CD, Krzewinski J, Burns JL. Cleaning home nebulizers used by patients with cystic fibrosis: is rinsing with tap water enough? J Hosp Infect 2001;49(3):229-230.

11. Jakobsson BM, Onnered AB, Hjelte L, Nyström B. Low bacterial contamination of nebulizers in home treatment of cystic fibrosis patients. J Hosp Infect 1997;36(3):201-207.

12. Hamill RJ, Houston ED, Georghiou PR, Wright CE, Koza MA, Cadle RM, et al. An outbreak of Burkholderia (formerly Pseudomonas) cepacia respiratory tract colonization and infection associated with nebulized albuterol therapy. Ann Intern Med 1995;122(10): 762-766.

13. Sanders CV Jr, Luby JP, Johanson WG Jr, Barnett JA, Sanford JP. Serratia marcescens infections from inhalation therapy medications: nosocomial outbreak. Ann Intern Med 1970;73(1):15-21.

14. Ramsey AH, Skonieczny P, Coolidge DT, Kurzynski TA, Proctor ME, Davis JP. Burkholderia cepacia lower respiratory tract infection associated with exposure to a respiratory therapist. Infect Control Hosp Epidemiol. 2001;22(7):423-426.

15. Vassal S, Taamma R, Marty N, Sardet A, d'Athis P, Brémont F, et al. Microbiologic contamination study of nebulizers after aerosol therapy in patients with cystic fibrosis. Am J Infect Control 2000;28(5): 347-351.

16. Cobben NA, Drent M, Jonkers M, Wouters EF, Vaneechoutte M, Stobberingh EE. Outbreak of severe Pseudomonas aeruginosa respiratory infections due to contaminated nebulizers. J Hosp Infect 1996;33(1):63-70

17. Tablan OC, Anderson LJ, Besser R, Bridges C, Hajjeh R, CDC, Healthcare Infection Control Practices Advisory Committee. Guidelines for preventing health care-associated pneumonia 2003: recommendations of the CDC and the Healthcare Infection Control Practices Advisory Committee. MMWR Recomm Rep 2004;53(RR-3): $1-36$.

18. Craven DE, Lichtenberg DA, Goularte TA, Make BJ, McCabe WR. Contaminated medication nebulizers in mechanical ventilation circuits. Source of bacterial aerosols. Am J Med 1984;77(5):834-838.

19. Mastro TD, Fields BS, Breiman RF, Campbell J, Plikaytis BD, Spika JS. Nosocomial Legionnaires' disease and use of medication nebulizers. J Infect Dis 1991;163(3):667-671.

20. Reboli AC, Koshinski R, Arias K, Marks-Austin K, Stieritz D, Stull TL. An outbreak of Burkholderia cepacia lower respiratory tract infection associated with contaminated albuterol nebulization solution. Infect Control Hosp Epidemiol 1996;17(11):741-743.
21. Healthcare Infection Control Practices Advisory Committee, Centers for Disease Control and Prevention (U.S.). Guidelines for preventing health-care-associated pneumonia, 2003 recommendations of the $\mathrm{CDC}$ and the Healthcare Infection Control Practices Advisory Committee. Respir Care 2004;49(8):926-939.

22. Centers for Disease Control and Prevention. Guideline for prevention of nosocomial pneumonia. Respir Care 1994;39(12):1191-1236.

23. Hess DR. Guidelines for preventing health-care associated pneumonia, 2003: buyer beware! Respir Care 2004;49(8):891-893.

24. Ari A, Restrepo RD, American Association for Respiratory Care. Aerosol delivery device selection for spontaneously breathing patients: 2012. Respir Care 2012;57(4):613-626.

25. Standaert TA, Morlin GL, Williams-Warren J, Joy P, Pepe MS, Weber A, Ramsey BW. Effects of repetitive use and cleaning techniques of disposable jet nebulizers on aerosol generation. Chest 1998; 114(2):577-586.

26. Weber DJ, Rutala WA, Sickbert-Bennett EE. Outbreaks associated with contaminated antiseptics and disinfectants. Antimicrob Agents Chemother 2007;51(12):4217-4224.

27. Friedman C. Infection prevention and control programs. In: Carrico R. APIC text of infection control and epidemiology, 2011. http:// text.apic.org/item-2/chapter-1-infection-prevention-and-controlprograms/basic-principles. Accessed March 20, 2014.

28. Saiman L, Siegel JD, LiPuma JL, Brown RF, Bryson EA, Chambers $\mathrm{MJ}$, et al. Infection prevention and control guideline for cystic fibrosis: 2013 update. Infect Control Hosp Epidemiol 2014;35(Suppl 1):S1-S67.

29. Neel S, Tauman A. Can successful implementation of the common canister program deliver cost containment and improved infection control? Hosp Pharm 2012;47(9):700-711.

30. Hess DR. Aerosol delivery devices in the treatment of asthma. Respir Care 2008;53(6):699-723; discussion 723-725.

31. Cohen HA, Cohen Z, Pomeranz AS, Czitron B, Kahan E. Bacterial contamination of spacer devices used by asthmatic children. J Asthma 2005;42(3):169-172.

32. Mitchell JP, Coppolo DP, Nagel MW. Electrostatics and inhaled medications: influence on delivery via pressurized metered-dose inhalers and add-on devices. Respir Care 2007;52(3):283-300.

33. Piérart F, Wildhaber JH, Vrancken I, Devadason SG, Le Souëf PN. Washing plastic spacers in household detergent reduces electrostatic charge and greatly improves delivery. Eur Respir J 1999;13(3):673678.

34. Slader CA, Reddel HK, Bosnic-Anticevich SZ. Lack of awareness of need to clean CFC-free metered-dose inhalers. J Asthma 2004;41(3): 367-373.

35. Bamber MG. Difficulties with CFC-free salbutamol inhaler. Lancet 1996;348(9043): 1737.

36. Mabbott FA, Mullen AB, Smith A, Smith G, Boyter AC. Qualitative analysis of microbial contamination of inhalers. J Hosp Infect 2011; 77(3):277-278.

37. Krueger-Parkinson R. Right language. The challenge to improve health literacy: what RTs need to know to communicate effectively with patients. AARC Times 2005;29(5):41-43.

38. Davis TC, Mayeaux EJ, Fredrickson D, Bocchini JA Jr, Jackson RH, Murphy PW. Reading ability of parents compared with reading level of pediatric patient education materials. Pediatrics 1994;93(3):460468.

39. Fink JB, Rubin BK. Problems with inhaler use: a call for improved clinician and patient education. Respir Care 2005;50(10):1360-1374; discussion 1374-1375. 


\section{Device Cleaning and Infection Control in Aerosol Therapy}

\section{Discussion}

Berlinski: Thank you for the nice review. I have a couple of comments. One is that many of the instructions or package inserts of the nebulizers recommend using vinegar to clean the equipment, but I think that's a big no-no.

O'Malley: You are correct. Vinegar is a no-no. Vinegar is not a recommended disinfectant.

Berlinski: But many devices out there have that recommendation. With respect to cleaning the PEP [positive expiratory pressure] devices, because that is really time consuming, if you put a bacterial filter between the mouthpiece and the device, why would you need to do that? You don't run any aerosols through the device. Why would you need to open it up to clean it?

O'Malley: In the hospital or in the home?

Berlinski: Hospital. I can get a \$1 disposable filter that you put between (on that device you showed there, or even the one that did not open), but if you don't run aerosols, which you probably shouldn't be doing anyway, you're not breathing, and you're using a filter, I'm not sure I see the need of going through all the trouble. The problem is that the parts are extremely complex, and the likelihood of this being achieved is probably low with the current resources that are given. You just stated that you don't have a dedicated RT [respiratory therapist] to do this for your pulmonary clinic, so that tells you a little bit about how this goes.

O'Malley: I did see a picture of a MetaNeb circuit with a filter, and I was confused about that because wouldn't it filter the aerosol particles? I wasn't sure about that, but if it's just a PEP device without an add-on aero- sol, I've always questioned, "Is it less harmful?" Since you're not including aerosol particles into the lungs, can one be less diligent about the cleaning and disinfecting? I'm not sure. Perhaps, but the PEP device does come in contact with mucous membranes, so it is a semi-critical medical device. In the hospital setting, we use these oscillating PEP devices, and we require that the patient or the caregiver clean it with sterile water and soap, rinse with sterile water, and let it airdry every evening. So if you use a filter, is that better than doing that? I don't know.

Berlinski: If you used a filter, you would probably just need to wash the mouthpiece.

O'Malley: Or replace it.

Berlinski: Or replace it, if you wanted. That would be a very inexpensive way.

O'Malley: It might be a better way; I'm going to look into that. Thank you.

Hess: The question I have is what evidence do we have that it matters? Do we know that any patient has ever had a bad outcome because of not cleaning the PEP device?

O'Malley: Bacterial contamination of home nebulizers is well documented, but there is no proof that a person got sick from personal equipment.

Hess: My concern is that we come up with these guidelines that seem to make sense (and I would agree that it seems to make sense), but early in my career, we thought we needed to change the ventilator circuit every day for infection-control purposes. And then we learned that the best thing was to not change it at all, as far as infection control. Throwing in an expense like a filter or time for cleaning, lacking the evidence that it makes a difference, concerns me. The other one is wiping off a mouthpiece with an alcohol wipe. I've never done that in 40 years. Maybe I should? But again, what's the evidence that it makes a difference? When I do my next clinical shift, should I put a whole bunch of alcohol wipes in my jacket pocket so I can wipe off the nebulizers after the treatments?

O'Malley: There are no data to support the specific practice of wiping the mouthpiece of the nebulizer with alcohol after use; however, if I'm a patient in a hospital bed and they handed me the mouthpiece I used 4 hours earlier and it looks dirty and feels crusty, I would really appreciate someone taking the time to clean my mouthpiece with an alcohol pad after I use it.

Berlinski: The issue is that studies have shown that, in patients with $\mathrm{CF}$ [cystic fibrosis], the same bacteria found in their oropharynx and lungs grow in the nebulizer, so their concerns are with multidrug-resistant bacteria. You know that nebulizers disseminate droplets more than 3 feet away from the patient, so there's risk of transmission to other patients. There's also the risk of sending these bacteria present in the oropharynx deeper into the lungs. I think that's where the concern stems from and why these guidelines are being developed.

Hess: The same thing applies with ventilator circuits: patients exhale whatever is in their lungs into the circuit and then breathe it in again. Is there any evidence that that results in recolonization of patients?

\$ Fink: I remember back at the time we were looking at ventilator circuits, we had been using the PB [PuritanBennett] Cascade with the bubble humidifiers, and people identified that it made micro-aerosols and that was a source of contamination. So we went to HMEs [heat-and-moisture exchang- 


\section{Device Cleaning and Infection Control in Aerosol Therapy}

ers] and pass-over humidifiers to eliminate mechanisms to transmit the bugs back to the patient unless it was contaminated condensate that you poured back down the tube. That's why your study was so pivotal in terms of needing to change the circuits. I don't think we would be able to do that as effectively if we were still using humidifiers that made aerosols.

Hess: We were. I can tell you that in our study ${ }^{1}$ published 20 years ago on the frequency of changing ventilator circuits, we were still using Cascade humidifiers.

Berlinski: I'd like to go back to your question. Probably the difference between patients with $\mathrm{CF}$ and patients receiving mechanical ventilation is that the acquisition of certain pathogens in CF is associated with deterioration of your clinical status, namely, $P$. aeruginosa, multidrug-resistant organisms, Burkholderia cepacia. There's a big group of pathogens that you really don't want to acquire, and the reality is that even though therapists use gowns and gloves for every single procedure when you are in the room of a patient with $\mathrm{CF}$, there's still risk of cross-contamination. That's probably one difference between those 2 conditions.

$\ddagger$ Fink: Can I ask a different question? One of my biggest concerns in the hospital is there's really no safe place to clean, wash, and disinfect nebulizers at the bedside. It's a germy nasty place, and we generally take these things that are partially air-dried, stick them in a bag, and let them fester between treatments, which has always scared me a little bit. Your MDI [metered-dose inhaler] information was really interesting. A lot of places, because of the high cost of MDIs, have started sharing common canisters. I'm wondering whether there's any evidence that supports that practice in terms of carrying bugs from one patient to the other with a shared canis- ter. One last thing: dishwashers for cleaning? I don't know where we started with that, but I look at my dishwasher, and there's all this stuff (bits of food) from the last couple of months as small particulate down in the recesses of the device that may not be infected but certainly provide a great growth medium. For vibrating mesh nebulizers, I think these particles are at risk to clog the mesh. Is it really safe and effective to use dishwashers for home care for cleaning rather than some of these other methods?

O'Malley: When I share with families the options for disinfection, most are not comfortable with the dishwasher for all the reasons that you just mentioned, but there are some who have these state-of-the-art, very hightech dishwashers. There's no temperature probe on it, but they say the steam billows out for 45 minutes, and when the cycle is done and you open up that stainless steel door, it's shining bright clean and dry. Okay, if I had that kind of dishwasher, I would be comfortable using it as a disinfectant for my respiratory care equipment.

\$ Fink: Is there any evidence to support dishwashers being used?

O'Malley: It's about temperature and time: $158^{\circ} \mathrm{F}$ for 30 minutes.

Fink: So it's the assumption that the temperature and time are effective from other studies being applied to the dishwasher?

O'Malley: It is not an assumption that the time (30 minutes) and the temperature $\left(158^{\circ} \mathrm{F}\right)$ will disinfect the equipment, but it may be an assumption that your dishwasher achieves this! As far as the canister, are you talking about the actual MDI medication canister? Isn't that single-patient use only?

\$ Fink: Some hospitals have gone to canister sharing.
O’Malley: Ewww.

$\$$ Fink: I had the same response!

O'Malley: There is the common canister protocol, which is to wipe the canister and boot well with $70 \%$ alcohol after each patient and before each use, and evidence shows that this results in no growth of bacteria on the equipment, but when we are still struggling to get people to use good aseptic technique and good handwashing technique, I would think that canister sharing has a high possibility for crosscontamination. And I would say the same for the instruction canisters, the placebos. If I'm teaching someone how to use an MDI, I go to the Pyxis and get out a brand new 60-actuation MDI and a new spacer, and I deliver the dose. If it's a first-time user, it's also an opportunity to make sure they tolerate the medication.

Restrepo: I'd like to respond to Dean's comment. I am with you; I think we pay a lot of attention to all these things. Don't get me wrong; it's one thing to put bacteria intentionally into a closed system with poor care. That's not the case; I don't think there's a discussion there. The second thing is how much care is really needed to insert bacteria into the circuit for them to cause pneumonias. We look at the risk factors for VAP (ventilator-associated pneumonia), which is one of the big concerns, and this doesn't really come up as a target unless you have soiled the circuit. I think that a lot of this evidence comes from the suggestion that the lungs are sterile; we know that the microbiological story has shown us that the lungs are really not sterile. All these bacteria are there, and they're going back and forth. Would that be the same premise of what happens when you aerosolize and what happens when you drink tap water? That's not the only way that bacteria can go directly into the lungs. I think the story outside is very different from that in the hospital, but 


\section{Device Cleaning and Infection Control in Aerosol Therapy}

the story in the hospital, in my mind, is how you avoid direct transmission of bacteria. I think the recommendations are really important, and the barrier recommendations are critical. If you don't wear gloves, that's where you can really transmit. How much of all this is necessary? I think that's why there's a big movement toward disposable products. In the out-patient setting, I think it's less critical, but the hygiene of every person is different, and we need to have standards. I think this is what you're really trying to say here: when you have standards, below this line is bad, but this hyper-clean is impossible. It's very impractical, but as Dean says, what is the evidence that we have to go to this extreme? When you have a lot of recommendations for a lot of things, someone will make a mistake, so we're making something that is already difficult way more complicated.

Laube: Do we have to worry about whether these devices say they're dishwasher safe before we put them into a dishwasher?
O'Malley: Yes, you'd want to make sure that the device would maintain its integrity.

Laube: Would that be stated somewhere by the manufacturer? Would patients know that?

O'Malley: Right now, one of the spacer devices by Monaghan is dishwasher safe, and it's in their instructions. It is important to make sure that the option you choose for disinfection is permitted by the manufacturer.

Berlinski: Regarding shared canister use, if I'm not mistaken, I think that's against The Joint Commission regulations because every medication has to be labeled with a dose and the patient's name. So that goes against that principle.

\$Fink: But The Joint Commission also says, for disposables for instance, there are caveats that if you have local information that supports recycling single-patient use devices for reuse or if you have local evidence that it's safe and effective to do, it's okay for your institution, which opens up a lot of questions. For instance, as you showed in your slide, some people change after every dose, some people change once a day, and others go a week with a nebulizer that hasn't been cleaned or changed out. Some of the state licensing groups are asking institutions to justify their change policy? While I understand you shouldn't do routine surveillance, we should probably provide some reasonable culture guidelines and methodologies to people to justify their change policies.

O'Malley: Agreed. Further research is needed where there is a lack of evidence to support our practices.

$\ddagger$ James B Fink PhD RRT FAARC, James B Fink LLC, San Mateo, California, and Division of Respiratory Therapy, Georgia State University, Atlanta, Georgia, representing Aerogen.

\section{REFERENCE}

1. Hess D, Burns E, Romagnoli D, Kacmarek RM. Weekly ventilator circuit changes. A strategy to reduce costs without affecting pneumonia rates. Anesthesiology 1995; 82(4):903-911. 